\title{
Interlanguage Pragmatic Motivation in EFL Context
}

\author{
Widya Caterine Perdhani \\ Malang State University \\ Universitas Brawijaya Malang \\ e-mail: caterine_widya@ub.ac.id
}

\begin{abstract}
:
This research sets out to explore the Interlanguage pragmatic motivation in EFL to their pragmatic production. This research is focus on the construct and impact of Interlanguage pragmatic motivation in EFL to their pragmatic production. The participants of the study were the university students chosen randomly from among intermediate EFL learners. There are three instruments in this study; there will be different types of analyses. Both general and speech-act-specific motivation questionnaires will be analysed by using factor analysis on a five-point Likert scale (1-5). Skewness and kurtosis will be calculated to investigate whether the questionnaires and the WDCT items fell within the normal range. Regression analysis will be done to measure how well general pragmatic motivation and Speech-act-specific motivation could predict pragmatic production. Several conclusions can be drawn from the resent study. First, language learners possess a specific type of motivation for the acquisition of interlanguage pragmatics, called pragmatic motivation, which refers to two interrelated types of motivation: general pragmatic motivation and speech-act-specific motivation. Second, EFL learners are strongly motivated to acquire and develop English pragmatic features, i.e. their pragmatic motivation is high; however, they do not have the necessary pragmatic knowledge. Third, predicting EFL learners' pragmatic production based on their speech-act-specific motivation is somehow possible since both pragmatic production and speech-act-specific motivation focus on learners' illocutionary competence, i.e. language functions and speech acts.
\end{abstract}

Keywords: interlanguage, pragmatic competence, speech act 


\section{Introduction}

The issue of individual differences has been explored as an indispensable aspect of second language acquisition (SLA). Among individual variables, motivation for language learning has been considered as an important area of inquiry. This personality factor indicates that learners differ in the degree of their impetus for the learning of a second/foreign language. A great number of studies have investigated the role of motivation in SLA (e.g. Dornyei, 1990, 2001; Kramsch, 2001; Oxford and Shearin, 1994; Shumann, 1998). However, the role of motivation in the acquisition of interlanguage pragmatics has only recently been investigated, and a few studies have been conducted in this regard(Cook, 2001; LoCastro, 2001; Niezgoda and Rover, 2001; Tagashira et al., 2011 Takahashi, 2001, 2005). These studies investigated the relationship between general language learning motivation and the acquisition of interlanguage pragmatics (ILP). They measured general language learning motivation using questionnaires in which integrative, instrumental, intrinsic, and extrinsic types of motivation were the main constructs (e.g. Schmidt et al., 1996). These constructs deal with the reasons for learning a second/ foreign language, particularly in learning grammar and vocabulary, personal goals, attitudes toward language class and language teacher, anxiety, learning preferences, and even learning strategies. However, no study has ever been reported about the motivation for the acquisition and development of pragmatic competence and its components. In other words, learners' motivation for the acquisition of language functions, speech acts and their realization patterns, pragmalinguistic forms, and sociopragmatic norms have never been investigated. Thus, it is necessary to investigate a new construct which accounts for motivation for the acquisition of L2 pragmatics so that we will be able to describe and measure such a construct among EFL learners and its impact on speech act production.

Pragmatic competence is part of communicative competence. The models of communicative competence of Canale (1983) and Bachman (1989), inspired by Hymes' (1972) construct of sociolinguistic competence, are evidence of attempts to integrate L2 pragmatic norms and behavior into a theory of second/ foreign language development.To determine the interlanguage knowledge as in case of the linguistic competence of child first language (L1) learners and adult native speakers, interlanguage competence cannot be examined directly. L2 learners need to develop their pragmatic competence in order to use language appropriately according to the socio-cultural norms of the L2 community.Instead, information about the nature of interlanguage competence can only be derived indirectly, through an examination of interlanguage performance data. In conjunction with this expansion of what it means to know a language, questions arise with regards to individual differences and the role of attitudes, motivation, and learners' willingness to adopt L2 standards for linguistic action. Therefore, motivation, as an individual difference, plays an important role in the process of ILP acquisition.

Interlanguage pragmatics (ILP), the study of the development and use of strategies for linguistic action by non-native speakers (NNSs), has a peculiar status in second language research. Unlike other areas of second language study, which are primarily 
concerned with acquisitional patterns of interlanguage knowledge, the great majority of studies in ILP have not been developmental. Rather, focus is given to the ways NNSs' pragmalinguistic and sociopragmatic knowledge differs from that of native speakers (NSs) and among learners with different linguistic and cultural backgrounds. To date, ILP has thus been primarily a study of second language use rather than second language learning (Kasper \& Schmidt, 1996).

A study investigates the EFL students' production of speech act and compares two popular measures of second language pragmatic competence: production questionnaires and role plays (Sasaki, 1997). Twelve Japanese university students representing three different English proficiency levels responded to both measures for the same four request and four refusal situations. The production questionnaire and role play elicited somewhat different production samples from the students. Role plays induced longer responses, and a larger number and greater variety of strategies/formulas, than production questionnaires. These differences appear to be caused by the interactive nature of role plays. The low correlation probably resulted not only because the two methods produced different responses, but also because the role plays responses provided additional audio-visual information, which might have affected the raters' evaluations. The results suggest that production questionnaire scores cannot be simply substituted for role plays. Another study investigates the integrative motivation and instrumental motivation. The analysis studies whether other aspects, such as the degree in which the specificity of the courses or the introduction of an immersive virtual world can modify the students' self-efficacy beliefs (Carrio \& Mestre, 2013). Two groups of students were selected to carry out a qualitative study on motivation. The activities and results obtained in both groups were contrasted in order to determine if the two basic types of motivation played a relevant role in second language acquisition. It can be stated that the results showed that the pre-conceived beliefs of learners were relevant in certain activities, i.e. Collaborative, web based activities; and in the demand for a definite syllabus of the course cores.

An interlanguage pragmatic motivation has been investigated from the general pragmatic motivation and speech-act-specific motivation to reveal the students' pragmatic production (Tajeddin and Moghadam, 2012). The construct of interlanguage pragmatic motivation deal with the reasons for learning a second/ foreign language, particularly grammar and vocabulary, personal goal, attitudes toward language class and language teacher, anxiety, learning preferences, and even learning strategies. Meanwhile the impact is on pragmatic acquisition.

It is noteworthy that all the above-mentioned studies investigated the relationship between language learning motivation in general and ILP acquisition. Hence, they do not account for EFL learners' motivation specific to pragmatic acquisition. In other words, the above-reported studies did not describe language learners' specific motivation to acquire and develop pragmatic competence and its components. Moreover, no findings have been reported about the motivation for the acquisition and development of speech acts and their realization patterns, pragmalinguistic forms, and sociopragmatic norms. Thus, it is important to investigate and model the 
construct of pragmatic motivation and to describe and measure its impact on pragmatic acquisition among EFL learners.

\subsection{Research Questions}

1. What is the construct of general pragmatic motivation and speech-act-specific motivation among EFL learners?

2. What is the status of general pragmatic motivation and speech-act-specific motivation among EFL learners?

3. Does general pragmatic motivation predict EFL learners' pragmatic production?

4. Does speech-act-specific motivation predict EFL learners' pragmatic production?

\subsection{Significances of the Research}

The findings of the research are expected to be beneficial for language learners for the acquisition of pragmatic competence and to contribute to the body of knowledge specifically on pragmatics in ELT particularly dealing with speech act production.

Theoretically, this research will provide better understanding for motivation research, acquisition of interlanguage pragmatics, EFL teachers, and materials developers. As far as the theories of motivation are concerned, pragmatic motivation must be considered as a type of motivation which brings about individual differences among language learners. Thus this type of motivation can be investigated, compared, and contrasted with other types of motivation. It also helps researchers have a better account of the process of second/foreign language acquisition. With regard to the acquisition of interlanguage pragmatics, the study highlights EFL learners' need to acquire and develop interlanguage pragmatics.

\section{Research Methodology}

The research is classified as second language acquisition (SLA) research, since it observed the acquisition of second language pragmatic competence of Indonesian EFL learners.

\subsection{Participants}

The participants of the study were the university students chosen randomly from among intermediate EFL learners. They will take a standardized test of English proficiency. The participants will also be interviewed and rated based on Brown's (2001) five-component Model.

\subsection{Instruments}

The first step in developing an instrument to measure pragmatic motivation is to review the SLA literature on motivation and ILP. Based on the review, the construct of pragmatic motivation will be defined as the driving force to acquire L2 pragmalinguistic and sociopragmatic competencies, i.e. the impetus to learn the appropriate use of L2 in real-world situations, appropriate L2 pragmatic strategies, L2 speech acts and their appropriate realization patterns and production, L2 
politeness strategies, and L2 pragmatics routines. Next, this type of motivation will be operationally defined and realized into two types of questionnaires.

\subsection{General Pragmatic Motivation Questionnaire (GPMQ)}

The general pragmatic motivation questionnaire focused on the motivation for the learning of L2 pragmatics. Thus, cultural familiarity, politeness strategies, familiarity with speech acts and situations, and strategies for meaning conveyance will be investigated through different items on a five-point Likert scale, ranging from 'strongly agree' to 'strongly disagree.' The items checked whether the learners are motivated to focus on such important aspects of language use, or they were just motivated to add to their knowledge of vocabulary and grammar.

\subsection{Speech-act-specific Motivation Questionnaire (SASMQ)}

The speech-act-specific motivation questionnaire focused on the motivation for three speech acts of request, refusal, and apology. It will be consisted of 20 items in three separate sections: five items will test the motivation to make requests; six items will measure the degree of motivation to make refusals, and nine items will test motivation to apologize. The rationale behind the construction of the items is to measure EFL learners' motivation for the acquisition of speech acts.

\subsection{Written Discourse Completion Task (WDCT)}

The written discourse completion task consisted of 15 situations, focusing on three speech acts of request, refusal, and apology. The production of each speech act measured through five situations. The situations were adapted from previous studies (Beebe et al., 1990; Hill, 1997; Hudson et al., 1995; Jianda, 2006; Suh, 1999; Takahashi, 1998, 2001). To do the DCT task, the subjects will be given the instruction to write down what they think they would say in the described situation.

For the study, a questionnaires on a 5 -point Likert scale $(5=$ strongly agree; $4=$ agree; 3= undecided; 2= disagree; 1=disagree) was adapted from Tajjedin (2010)'s questionnaire. The questionnaire consists of 8 subscales of 56 items in total. This questionnaire originally had 72 items, but after trying out on 5 February 2014, its validity and reliability were measured. The try out was administered to fifteen advanced EFL students who were excluded from the participants.

From the try out, the questionnaire validation was measured based on Pearson Product moment correlation, among them 16 items were not valid, and they were eliminated. In accordance to this, the reliability indices of the questionnaire sections follow, (1) communication apprehension in EFL group work (7 items, $\alpha=.888$ ); (2) self-perceived communicative competence in EFL group work (7 items, $\alpha=.871$ ); (3) positive beliefs about the value of group work (5 items, $\alpha=.861$ ); (4) negative traditional instruction orientation (6 items, $\alpha=.739$ ); (5) beliefs of group work usefulness (17 items, $\alpha=.962$ ); (6) willingness to communicate in EFL group work (9 items, $\alpha=.918)$; (7) instrumental motivation (3 items, $\alpha=.638$ ); (8) integrative motivation ( 2 items, $\alpha=.930$ ). 
The WDCT was validated by three colleges as an inter-rater. After having the expert validation, the WDCT was try out to the $15 \mathrm{EFL}$ students to know their understanding about the tasks.

The questionnaire sections above are mainly utilized to elicit information regarding to students' willingness to communicate in English in group work activities. First, belief about EFL group work consists of positive beliefs about the value of group work, negative traditional instruction orientation, and beliefs of group work usefulness. Second, learning motivation includes instrumental and integrative motivations. Third, communicative confidence in EFL group work deals with communication apprehension and self-perceived communicative competence in EFL group work. Fourth, willingness to communicate in EFL group work has several items to indicate students enthusiasm to communicate in English language.

Another instrument used is an interview. The questions are taken from items in the questionnaires that are modified to obtain sufficient information. The interview is aimed at confirming the results of the study which do not match with the underlying theories or willingness to communicate adapted from Fushino (2010).

\subsection{Data Collection}

Before distributing the questionnaire the applicant will be selected based on their TOEFL score. The applicants whose score 450-500 are categorize in an intermediate level. Then they are given the questionnaire. The first questionnaire given to the applicant is General Pragmatic Motivation Questionnaire. The second questionnaire given is speech-act-specific motivation questionnaire.

After the applicants finished completing the questionnaires they need to do the written discourse completion task in the classroom. The elicitation instrument used for data collection is the discourse completion questionnaire (DCT hereafter). The researcher, knowing that the written DCT has been subject to criticism for its inadequateness to represent the actual wording used in real interaction, the prosodic, and nonverbal features of oral interaction, and the number of repetitions and elaborations that are found in naturally occurring interactions (Bardovi- Harlig and Hartford, 2005).

\subsection{Data Analysis}

There are three instruments in this study; there will be different types of analyses. Both general and speech-act-specific motivation questionnaires will be analysed by using factor analysis on a five-point Likert scale (1-5). Skewness and kurtosis will be calculated to investigate whether the questionnaires and the WDCT items fell within the normal range. Regression analysis will be done to measure how well general pragmatic motivation and Speech-act-specific motivation could predict pragmatic production.

WDCTs used in this research have a six-point rating scale developed by Taguchi (2006). In this rating scale, scores for appropriateness range from 0 to 5 . The scale embodies the appropriate use of linguistic expressions, proper level of directness, proper level of politeness, pragmalinguistic accuracy, and sociopragmatic aspects of 
speech act production in assigning scores. Appropriateness in this scoring rubric deals with the appropriate performance of speech acts in a social context, which includes pragmalinguistic and sociopragmatic considerations (Kasper, 1992).

\section{Findings and Discussion}

The first research question was concerned with the construct of general pragmatic motivation and speech-act-specific motivation among EFL learners. To address the question, a factor analysis was run.

Factor Analysis of General Pragmatic Motivation Questionnaire (GPMQ). The factor analysis was carried out, using a principal component analysis with oblique rotation $(N=300)$. To determine the number of factors to be extracted in the general pragmatic motivation questionnaire, a few points were taken into consideration to ensure that the minimum eigenvalue was 1.0, that each factor accounted for at least $2.5 \%$ of the total variance, and that the minimum loading of every item on each factor was .38 .

As a result, 12 factors were obtained which accounted for $60.33 \%$ of the total variance in the learners' general pragmatic motivation (Table 1). Among the 12 factors, factor 1 had the largest variance $(V=16.66)$, whereas factor 12 had the smallest variance $(V=2.51)$.

Factor Analysis of Speech-act-specific Motivation Questionnaire (SASMQ). To determine the number of factors to be extracted in all SASMQs, the minimum eigenvalue was 1.0 , each factor accounted for at least $2.5 \%$ of the total variance, and the minimum loading of every item on each factor was .30. In Request-SASMQ, one factor was obtained which accounted for $55.61 \%$ of the total variance. In RefusalSASMQ, one factor was obtained which accounted for $56.77 \%$ of the total variance. Finally, in Apology-SASMQ, like the other two speech acts, one factor was obtained which accounted for $46.27 \%$ of the total variance. As a result, it was observed that every subsection (Request-SASMQ, Refusal- SASMQ, and Apology-SASMQ) loaded on one factor only, which confirms specific motivation for performing any of the speech acts. Table 2 shows factor loadings and Cronbach alpha internal consistency reliability for the three subsections.

The second research question was, 'What is the status of general pragmatic motivation and speech-act-specific motivation among EFL learners?' To address it, every participant's response to each item of the two types of questionnaires was analyzed. To this end, descriptive statistics were calculated. The total mean of the general pragmatic motivation questionnaire was 3.14. In the general pragmatic motivation questionnaire, among the 42 items, item 28 had the highest mean of 4.43 . To check the reliability of the questionnaire, Cronbach's alpha was run, and the reliability coefficient was observed to be high enough $(\mathrm{r}=.87)$. To ensure normality, skewness and kurtosis analysis was also run. By checking the skewness and kurtosis values for the questionnaire, its skewness and kurtosis indices were found to be within the normal range: -.39 and .98 , respectively. Since the questionnaire was on a 5-point Likert scale from 'strongly agree' to 'strongly disagree' and the mean score on the questionnaire was 3.14, it can be concluded that the participants of the study 
were highly motivated to acquire interlanguage pragmatics. An analysis of every item of the questionnaire revealed that the mean scores in 12 items.

Table 1. Descriptive Statistics for Speech-act-specific Motivation

\begin{tabular}{lllllllll}
\hline SASMQ & $\mathrm{N}$ & Min. & Max. & Mean & SD & Skewnes & Kurtosis & A \\
\hline Request & 75 & 2.60 & 5 & 4.06 & .60 & -.17 & -.58 & .7 \\
Refusal & 75 & 1.50 & 5 & 4.01 & .66 & -.85 & 1.71 & .8 \\
Apology & 75 & 2.89 & 5 & 4.02 & .48 & -.002 & -.31 & .8 \\
Total & 75 & 2.85 & 5 & 4.03 & .50 & -.12 & -.52 & .9 \\
\hline
\end{tabular}

The results showed EFL learners' high motivation to learn and use this specific speech act. The item with the highest mean was the first item, implying a high level of motivation to acquire pragmalinguistic forms of requests. As far as skewness and kurtosis are concerned, they fell within the normal range, which documents the normality of the distribution. The reliability of the subsection was also high, as Cronbach's alpha displayed a coefficient of .79. Statistics for the 'Refusal-SASM' questionnaire showed a mean of 4.01, proving learners' high motivation to acquire and use the speech act of refusal appropriately. Among the six items, item 3 represented the highest mean (4.2), which means that EFL learners had a high level of motivation to get familiar with politeness strategies and the sociopragmatic norms of making refusals. With regard to the last sub- section of motivation for the speech act of apology (Apology-SASM), the observed mean was 4.02. This, again, indicates that learners were highly motivated to learn how to produce apology appropriately in L2. Among the 9 items, item 1 has the highest mean, showing that appropriateness is a language use factor that EFL learners are highly motivated to acquire. In this questionnaire, item 8 had the highest standard deviation. The distribution was seen to be normal since skewness and kurtosis values did not fall beyond $+/-2$. As with the reliability of the questionnaire, Cronbach's alpha showed a high degree of reliability, with an index of .81. Adding the three subsections of questionnaires together, speech-act-specific motivation as a construct was also investigated. The total mean was seen to be 4.03 , which indicates high speech-actspecific motivation among the participants. The whole speech-act-specific motivation questionnaire was analyzed for reliability and Cronbach's alpha was observed to be .91 .

To see how well general pragmatic motivation can predict pragmatic production, data col- lected from written discourse completion tasks (WDCT) were first rated by one of the two researchers based on a 6-point Likert scale. Then to ensure the reliability of the participants' scores on pragmatic performance, $20 \%$ of the WDCTs were rated by an educated native speaker of English who was already trained to rate the WDCTS based on the framework. The reliability index showed a consistency of .83 between the researcher's rating and the native speaker's. Therefore, every participant's score in each situation and speech act was calculated. To check the reliability of WDCT, Cronbach's alpha was run, and the reliability coefficient for the total WDCT was observed to be high $[r=.92]$. To ensure normality, skewness and 
kurtosis analysis was also run, indicating the normality of the distribution. Table 5 shows the descriptive statistics for pragmatic production.

As it is displayed, the mean score was 2.54 in request, 2.26 in refusal, 2.46 in apology, and 2.54 in the total pragmatic production. This shows that EFL learners' performance on WDCT was only slightly above 2.5 . It means that the participants were not good at performing the three speech acts of request, refusal, and apology, although their scores ranged from 0 to 4.8 ; that is, they lacked the necessary sociopragmatic and pragmalinguistic knowledge to perform the speech acts.

The next step was to run a regression analysis to see whether pragmatic production could be predicted based on general pragmatic motivation. In this analysis, general prag matic motivation was considered constant (predictor) and the three speech act productions were dependent variables. Therefore, first, regression was run for general pragmatic motivation as the predictor and production of request as the dependent variable. As Table 6 displays, the participants' general pragmatic motivation could not predict their produc- tion of the speech act of request $[\beta=.06, t(75)=.52, p<.01]$. General pragmatic motivation explained a very small proportion of variance in request production in that the amount of variance overlap between GPM and production of request speech act was very low $\left[R^{2}=.06\right]$. As with the other speech acts, it was observed that GPM could not predict EFL learners' production of the speech act of refusal either $[\beta=.04, t(75)=.36, p<.01]$. The proportion of the variance explained by general pragmatic motivation was very low as well $\left[R^{2}=.04\right]$. Still another regression analysis had the same results too.

The third finding of the study revealed that EFL learners were highly motivated to acquire and develop L2 pragmatics. This seems reasonable because EFL learners in this study had already spent seven years at secondary school to acquire and develop English vocabulary, reading, and grammar, but not language use. They did not know how to refuse an invitation, for instance, although they had already acquired the words and structure(s). Therefore, the first thing EFL learners are motivated to acquire is how to use language appropriately. Their high pragmatic motivation can be a strong impetus for their noticing ability, which can be scaffolded by more pragmatically competent learners or teachers. As far as the two types of pragmatic motivation are concerned, it was found that EFL learners' speech-act-specific motivation is greater than general pragmatic motivation. This indicates the importance of speech acts and form-function relationships to EFL learners, who need to acquire both pragmalinguistic forms and sociopragmatic norms to be able to communicate in a second/foreign language.

The fourth finding of the study shed light on EFL learners' pragmatic production. It was found that EFL learners lack necessary L2 pragmatic knowledge; they are not aware of L2 pragmatic features, resulting in inappropriate use of language. One reason is lack of necessary interactions in many EFL contexts; EFL learners are not exposed to the authentic use of the target language. There are other reasons for their high motivation but low awareness of ILP as well. As mentioned before, there is no focus on language use in their school and even university syllabi; as a result, EFL 
learners do not receive any instruction on ILP and are not exposed to L2 use. There is also the problem of generalizing linguistic forms, lexical items, and sociopragmatic norms in different situations by EFL learners due to L1 transfer, resulting in inappropriate L2 use. Therefore, EFL learners' general pragmatic motivation cannot be indicative of their pragmatic knowledge, particularly their pragmatic production.

The last finding of the present study revealed that speech-act-specific motivation can predict EFL learners' pragmatic production to a small degree, despite the fact that their general pragmatic motivation does not reveal anything about their current level of pragmatic knowledge. The reason is that both speech-act-specific motivation and pragmatic production largely hinge upon speech acts as an important aspect of ILP. However, general pragmatic motivation encompasses pragmatic factors other than speech acts. It follows that the probability of predicting pragmatic production based on the motivation for that speech act is higher.

\section{Conclusions}

Several conclusions can be drawn from the resent study. First, language learners possess a specific type of motivation for the acquisition of interlanguage pragmatics, called pragmatic motivation, which refers to two interrelated types of motivation: general pragmatic motivation and speech-act-specific motivation. This newly investigated construct differs from general language learning motivation and does not consider language learners' motivation for the acquisition of the second/foreign language as a whole. However, pragmatic motivation describes various aspects of pragmatic competence development.

Second, EFL learners are strongly motivated to acquire and develop English pragmatic features, i.e. their pragmatic motivation is high; however, they do not have the necessary pragmatic knowledge. This indicates that EFL learners are able to identify their real communication needs; they know that knowledge of vocabulary and grammar does not guarantee the appropriate use of language. Nevertheless, they lack the necessary ability for language use, while they may be good at the four skills, for instance.

Third, predicting EFL learners' pragmatic production based on their speech-actspecific motivation is somehow possible since both pragmatic production and speech-act-specific motivation focus on learners' illocutionary competence, i.e. language functions and speech acts. On the other hand, predicting pragmatic production based on general pragmatic motivation is largely impossible. To sum up, it can be concluded that high pragmatic motivation does not necessarily imply high pragmatic ability. 


\section{References}

Ames, C., \& Ames, R. (1989). Research in motivation in education. San Diego: Academic Press.

Bachman, L. F. (1989). The development and use of criterion-referenced tests of language ability in language program evaluation. In R. K. Johnson (Ed.) (1989). The Second Language Curriculum. Cambridge: Cambridge. University. Press.

Bialystok, E. (1993). Symbolic representation and attentional control in pragmatic competence. In G.

Canale, M. (1983). From communicative competence to communicative language pedagogy. In Richard, J. C. \& Schmidt, R. W. (Eds.), Language and communication. London and New York: Longman. 2-27.

Gardner, R.C. (1985). Social Psychology and Language Learning: the Role of Attitudes and Motivation. London: Edward Arnold.

Gardner, R.C. and Lambert, W.E. (1972). Attitudes and Motivation in SecondLanguage Learning. Rowley, MA: Newbury House.

Gardner, Tremblay, and Masgoret (1997). Towards a full Model of Second Language Learning: An Empirical Investigation. The Modern Language Journal, 344-362.

Tajeddin, Z. \& Moghadam, A.Z. (2012). RELC Journal, 43(3), 353-372

Takahashi S (1998) Quantifying requestive imposition: validation and selection of situations for L2 pragmatics research. Studies in Languages and Cultures 9: 135-59.

Takahashi S (2001) The role of input enhancement in developing pragmatic competence. In: Rose KR, Kasper G (eds) Pragmatics in Language Teaching. Cambridge: Cambridge University Press.

Kasper \& S. Blum-Kulka (Eds.), Interlanguage pragmatics (pp. 43-59). New York: Oxford University Press.

Lightbrown, P. M., and Spada, N. (1999). How languages are learned. Oxford: Oxford University Press.

Thomas, J. (1983). Cross-cultural pragmatic failure. Applied Linguistics, 4, 91-112.

Wildner-Bassett, M. (1984). Improving pragmatic aspects of learners' interlanguage. Tübingen: Narr.

Wolfson, N. (1989). Perspectives: Sociolinguistics and TESOL. New York: Newbury House. 